\title{
Association between Poor Ergophthalmologic Practices and Computer Vision Syndrome among University Administrative Staff in Ghana
}

\author{
Samuel Bert Boadi-Kusi ${ }^{D},{ }^{1}$ Sampson Listowell Abu, ${ }^{2}$ George Oppong Acheampong, ${ }^{3}$ \\ Peter Osei-Wusu Adueming $\left(\mathbb{0},{ }^{4}\right.$ and Emmanuel Kwasi Abu (1) ${ }^{1}$ \\ ${ }^{1}$ Department of Optometry and Vision Sceinces, School of Allied Health Sciences, College of Health and Allied Sciences, \\ University of Cape Coast, PMB, Cape Coast, Ghana \\ ${ }^{2}$ Department of Ophthalmology and Visual Sciences, School of Medicine, University of Alabama at Birmingham, Birmingham, \\ AL, USA \\ ${ }^{3}$ Eye Unit, DelCielo Optical Services, P. O. Box WY 2244, Kwabenya, Accra, Ghana \\ ${ }^{4}$ Laser and Fibre Optics Centre, Department of Physics, School of Physical Sciences, College of Agriculture and Natural Sciences, \\ University of Cape Coast., Cape Coast, Ghana
}

Correspondence should be addressed to Samuel Bert Boadi-Kusi; sboadi-kusi@ucc.edu.gh

Received 17 January 2019; Accepted 16 March 2020; Published 27 April 2020

Academic Editor: Chunrong Jia

Copyright $(92020$ Samuel Bert Boadi-Kusi et al. This is an open access article distributed under the Creative Commons Attribution License, which permits unrestricted use, distribution, and reproduction in any medium, provided the original work is properly cited.

\begin{abstract}
Aim. The aim of this study was to assess the prevalence of computer vision syndrome (CVS) and its associated ergonomic factors among university administrative staff in Ghana. Methods. A cross-sectional survey was conducted among 200 administrative staff of the University of Cape Coast. The procedure included a self-administered questionnaire, comprehensive ocular health examination, and assessment of computer workstation and lighting conditions. The prevalence of CVS among the subjects and the association between CVS and ergonomic practices were determined. Results. The mean age of the study sample was $31.0 \pm 4.7$ years, and the majority were males (56.0\%). The prevalence of CVS was among $103(51.5 \%)$ participants. Over a third of the respondents used computers for 6 or more hours daily. Significant association was found between CVS and poor ergonomic practices $(\chi=15.175, p=0.001)$. Conclusion. In addition to poor ergonomic office setup, university administrative staff spend several hours behind computer screens leading to the development of CVS. Increased awareness of CVS and adherence to recommended ergonomic practices are necessary to reduce the prevalence of CVS and ultimately enhance work satisfaction and productivity.
\end{abstract}

\section{Introduction}

The advent of computers in the 20th century is arguably the biggest technological revolution following the industrial revolution. Owing to their high efficiency and varied applications in the 21 st century, the use of computers has proliferated and become ineluctable at recreation facilities, homes, and workplaces such as the academic institutions $[1,2]$. The extensive use of computers, particularly at workplaces, has unfortunately compounded work-related health complaints and symptoms such as ocular problems, musculoskeletal discomfort, and stress [3, 4]. Vision-related problems are the most frequently reported health-related problems occurring in majority of computer users $[3,5,6]$. Prolonged daily use of computers has been identified to be a major precursor to developing computer vision syndrome (henceforth CVS) [6-9].

The American Optometric Association aptly defines CVS as a complex of eye and vision problems related to near vision tasks which occurs during and/or after the use of computers and prolonged viewing of the video display terminals (henceforth VDT) [10]. Common symptoms of 
CVS include but not limited to the following: dry and irritated eyes, excessive tearing, eye strain, hyperemia, burning sensation, blurred vision, diplopia, headache, glare sensitivity, transient poor color perception, and neck or shoulder pain $[1,2,10-12]$. These symptoms are noted to arise when the visual demands while working on a VDT exceed the abilities of the user [13]. Approximately 70\% of computer users suffer from CVS [3]. Izquierdo et al. reported that the global prevalence of CVS ranges from 25\% to 93\% [14].

The cause of visual problems experienced while using computers is multifactorial. While there is no strong evidence for causation [15], previous studies have reported that visual symptoms increased with the prolonged exposure to computer screens [16-18]. Uncorrected refractive error, presbyopia, and binocular vision abnormalities are additional factors associated with computer-related visual symptoms $[6,10]$. For instance, the incidence of CVS has been reported to be higher in both undercorrected and uncorrected ametropes than in emmetropes [19, 20]. Wiggins and Peers showed that uncorrected astigmatism produced a significant increase in CVS symptoms [21]. Environmental factors, poor computer design, and workplace ergonomics also contributed to the development of symptoms and complaints of CVS. In addition, poor lighting, imbalance between light of the computer screen and the surrounding, age, gender, and systemic diseases have also been enumerated by Rosenfield as environmental or external factors that risk the development of CVS [12].

Workplace ergonomics refers to the arrangement of equipment and furniture in an office space for users to work more efficiently and comfortably [22]. Visual or computer ergonomics on the other hand involves proper positioning of keyboard, monitor, mouse, chairs, desks, document folders, seat height, seat width and depth, seat material, backrest, materials in the office, armrests, leg room, thickness of work surface, footrest, document holder, wrist rests, and so on $[15,23,24]$. In a Nepalese study, users with their computer screens set below the eye level had significantly lower CVS case than those who viewed the screen at or above the eye level [25]. Mashige and colleagues studied ergonomic factors associated with CVS among nonpresbyopic university staff in South Africa [26]. They found that, in addition to poor ergonomic set up at workstations, participants were ignorant of ergonomic standards for computer use. Many researchers have prescribed measures to alleviate the symptoms of CVS. These include frequent blinking (12-18/minute), short-time breaks after every 20 minutes to look at distant object at least 20 feet away for 20 seconds (20-20-20 rule), adjustment of workstation, good sitting posture, appropriate lighting and screen brightness, and regular stretching of arms, leg, back, neck, and shoulders [10, 23, 27].

University administrative staff find themselves among the cohort of people who are more predisposed to developing CVS as they spend several hours daily behind computer screens. As office duties become more computer dependent, CVS will remain a significant health problem with its socioeconomic ramifications ranging from low productivity to poor job satisfaction. The aim of the present study was to determine the prevalence of CVS and identify the associated factors among university administrative staff in Ghana.

\section{Materials and Methods}

2.1. Study Population and Sampling. A cross-sectional study was carried out among the administrative staff of the University of Cape Coast in Ghana. Following study approval by the Institutional Review Board, 308 University Administrative staff were enumerated based on a systematic selective sampling technique using data obtained from the Human Resource Division of the University of Cape Coast. We recruited administrators, who in the preceding 6 months, averaged a daily minimum of 5 screen hours and had no systemic disease, binocular vision anomalies, or other ocular health conditions. Excluded participants were those aged 40 years and above, early presbyopes, refractive error above $\pm 3.75 \mathrm{D}$, corrected visual acuity worse than $6 / 6$, pregnancy, use of oral contraceptives, migraine, contact lens wear, and use of short-term or long-term systemic medication.

2.2. Data Collection. Each subject signed a consent form before participating in the study. The data collection required the subjects to undergo three procedures administered by three trained personnel. First, each participant answered an adopted and validated computer vision syndrome questionnaire (CVS-Q) [28]. The questionnaire probed into demographics, CVS symptoms, computercontact hours, breaks, and their ergonomic factors that might affect a respondent's comfort while using the computer. Study participants then underwent a comprehensive ocular health examination. This examination spanned from case history, visual acuity, ophthalmoscopy, refraction, and binocular vision assessment. This was done to ensure that participants satisfied the inclusion criteria set for the study. Based on the presented complaints, that is, the questionnaire responses, any participant who scored $\geq 6$ points, as indicated by the CVS-Q [28], was assigned to either a CVS case category or non-CVS category.

The third phase involved observation and measurement of ergonomic parameters at each administrator's workstation. The lighting around the computer workstation was measured with a calibrated digital light meter (Model 403125, Extech Instruments, USA). The following parameters (with their expected values) were recorded at each workstation:

(i) The viewing angle of the participant's eye level to the top of the computer screen $\left(10^{\circ}-20^{\circ}\right)$

(ii) The viewing angle of the participant's eye level to the center of the computer screen $\left(21^{\circ}-30^{\circ}\right)$

(iii) The viewing angle of the participant's eye level to the position of bottom of the screen $\left(31^{\circ}-40^{\circ}\right)$

(iv) The viewing distance from the horizontal to the top of the screen $(18-28 \mathrm{~cm})$

(v) The viewing distance from the horizontal to the bottom of the screen $(40-60 \mathrm{~cm})$ 
(vi) The viewing distance from the eye to horizontal center of the screen $(50-70 \mathrm{~cm})$

(vii) Viewing distance from the eye to the keyboard $(63-82 \mathrm{~cm})$

(viii) Height of the keyboard from the floor $(60-82 \mathrm{~cm})$

(ix) Light intensity between participant and computer $\left(75-150 \mathrm{Cd} / \mathrm{m}^{2}\right)$

(x) Light intensity of room $\left(200-500 \mathrm{Cd} / \mathrm{m}^{2}\right)$

These expected values were adapted from the ergonomic recommendations by the Workers' Compensation Board (WCB) of British Columbia [29], Oregon Occupational Safety and Health Agency [30], and ANSI/HFES 100-2007 [31]. Applicable viewing angles were computed in degrees using the formula: $\operatorname{Tan} \alpha=c / b$, where $\alpha$ equals the viewing angle, $b$ is the horizontal viewing distance from computer screen to participant, and $c$ is the viewing distance from top of computer screen to eye level. Any participant who recorded more than three measurements out of the ten parameters assessed, falling outside the recommended range, was classified under "poor ergonomic practice."

Finally, the spectra of radiations from some sampled computer monitor screens used by the administrative staff were measured in an experimental setup as schematically shown in Figure 1. The setup consisted of an optical fibre (BIF600-UV-VIS, Ocean Optics), a spectrometer from ocean optics (USB 4000 Spectrometer, Ocean Optics), and a laptop computer (Toshiba Laptop (3.0 GHz 8.0 GB, AMD A10$4600 \mathrm{M})$.

In acquiring the spectra of radiations from the sampled computer monitors, radiations were coupled into the optical fibre to the spectrometer which is connected to the laptop computer. The spectra from the radiations were then displayed on the laptop computer with the aid of spectra suite software. The spectra data were then extracted for further analysis.

2.3. Data Analysis. All data were entered and analyzed using Statistical Package for Social Sciences (SPSS version 21.0.). Seven out of ten measured workstation parameters within the expected range of values were deemed "good ergonomic practice," otherwise classified as "poor ergonomic practice." Using the Likert scale, frequency of CVS symptoms was rated from Never to Often or Always while intensity was rated from Moderate to Intense or Severe [28]. Descriptive statistics was used to explore the association between ergonomic factors and computer vision syndrome with the level of significance set at 0.05 .

\section{Results}

3.1. Participant Characteristics. Out of the 308 invitees, 200 subjects enrolled and completed the study (response rate-65.0\%). The remaining 108 either declined to participate in the study or could not complete the study due to busy work schedule. The mean age of the respondents was $31.0 \pm 4.7$ years (range $19-39$ years) and $56.0 \%$ of the 200 respondents were males. A majority $(76.0 \%)$ of the study population fell within the age category of 25-35 years. Almost half of the study population had worked with computers for more than 5 years. Fifty-nine percent of the respondents took a break from their computers whenever they felt tired. Of the 200 participants, 103 (51.5\%) were found to have symptoms of CVS. Nine percent more males than females had CVS. Sample characteristics are summarized in Table 1. More than one-third (37.5\%) of the participants aged 25-29 years were exposed to computer screens for at least 6 hours daily. The number of hours spent daily on using computers by participants in each age category are represented in Table 2.

3.2. Frequency and Severity of CVS Symptoms. The most frequent moderate to severe symptoms were burning sensation, foreign body sensation, eye pains, itching, and blurred vision. The distribution of the severity of CVS symptoms is shown in Table 3.

3.3. Ergonomic Measures and Association with the Prevalence of CVS. The ergonomic measurements, the expected values, and their association with good or poor practices are presented in Table 4 . There was a significant association between CVS case category and wrong viewing angle to the center of the computer screen in $73.5 \%$ of the respondents. The office illumination and light intensities emitted from the computers were found to be suboptimal in $99.0 \%$ of the workstations of those belonging to the CVS case group. Overall, poor ergonomic practices were observed at the workstations of $79.5 \%$ of the study population. We found a significant association between CVS and poor ergonomic practices $(X=15.175, p=0.001)$ as indicated in Table 5 .

Figures 2(a) and 2(b) illustrate the distribution of the measured light intensities from the computer monitor screens at some observed workstations. It is evident from the figures that blue light was being emitted from some of the sampled computer screens.

\section{Discussion}

The present study investigated the prevalence of computer visual syndrome and its associated risk factors among university administrative staff. This study population was chosen because they are part of a group of professionals who are at a greater risk of developing computer-related visual problems. The University of Cape Coast operates a decentralized administrative system that employs more administrative personnel among whom we recruited a sample for the study. Our study sample was comprised of more males than females and a mean age of $31.0 \pm 4.7$ years. Related studies done on CVS in Ghana [32], Nigeria [33], and South Africa [26] had similar age and gender distribution, except for the South African study [26] that had more females than males. The prevalence of CVS signs and/or symptoms was found to be $51.5 \%$ and the presence of CVS was associated with poor ergonomic practices or workstation setups.

In contrast to our study, a higher prevalence of CVS has been reported for different cohorts of computer users 


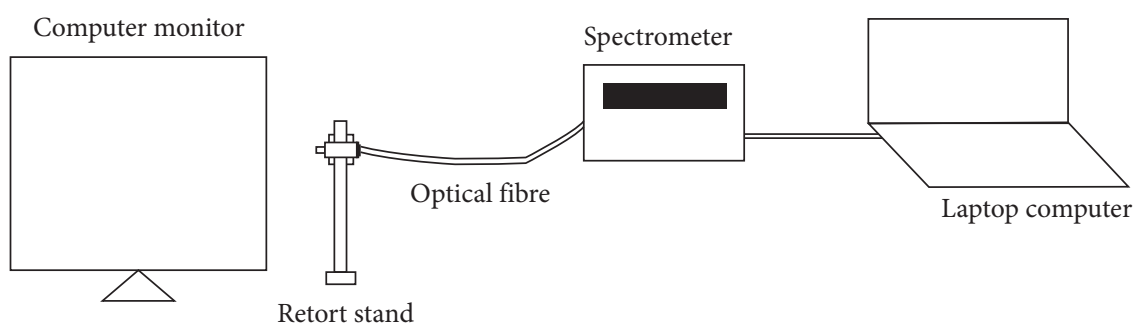

FIGURE 1: Schematic diagram for measuring light radiation from computer monitor.

TABLE 1: Distribution of parameters of administrators according to cases and noncases.

\begin{tabular}{|c|c|c|c|c|}
\hline \multirow{2}{*}{ Distributions } & & \multicolumn{2}{|c|}{ CVS status } & \multirow{2}{*}{ Total $(n, \%)$} \\
\hline & & Cases $(n, \%)$ & Noncases $(n, \%)$ & \\
\hline \multirow{5}{*}{ Age range } & $<0.25$ & $2(1.9)$ & $3(3.1)$ & $5(2.5)$ \\
\hline & $25-29$ & $46(44.7)$ & $39(40.2)$ & $85(42.5)$ \\
\hline & $30-35$ & $36(35.0)$ & $31(32.0)$ & $67(33.5)$ \\
\hline & $36-40$ & $19(18.4)$ & $24(24.7)$ & $43(21.5)$ \\
\hline & Total & $103(100)$ & $97(100)$ & $200(100)$ \\
\hline \multirow{3}{*}{ Gender } & Male & $56(54.4)$ & $56(57.7)$ & $112(56.0)$ \\
\hline & Female & $47(45.6)$ & $41(42.3)$ & $88(44.0)$ \\
\hline & Total & $103(100)$ & $97(100)$ & $200(100)$ \\
\hline \multirow{5}{*}{ Years of working with computer } & $2-5$ & $52(50.5)$ & $46(47.4)$ & $98(49.0)$ \\
\hline & $6-9$ & $27(26.2)$ & $23(23.7)$ & $50(25.0)$ \\
\hline & $10-14$ & $14(13.6)$ & $22(22.7)$ & $36(18.0)$ \\
\hline & $15-20$ & $10(9.7)$ & $6(6.2)$ & $16(8.0)$ \\
\hline & Total & $103(100)$ & $97(100)$ & $200(100)$ \\
\hline \multirow{5}{*}{ Educational background } & SHS & $2(1.9)$ & $1(1.0)$ & $3(1.5)$ \\
\hline & Diploma & $6(5.8)$ & $8(8.2)$ & $14(7.0)$ \\
\hline & First degree & $73(70.9)$ & $63(64.9)$ & $136(68.0)$ \\
\hline & Second degree & $22(21.4)$ & $25(25.8)$ & $47(23.5)$ \\
\hline & Total & $103(100)$ & $97(100)$ & $200(100)$ \\
\hline \multirow{5}{*}{ Musculoskeletal symptoms } & Never & $7(6.8)$ & $16(16.5)$ & $23(11.5)$ \\
\hline & Mild & $11(10.7)$ & $14(14.4)$ & $25(12.5)$ \\
\hline & Moderate & $22(21.4)$ & $22(22.7)$ & $44(22.0)$ \\
\hline & Severe & $63(61.2)$ & $45(46.4)$ & $108(54.0)$ \\
\hline & Total & $103(100)$ & $97(100)$ & $200(100)$ \\
\hline \multirow{5}{*}{ Computer breaks } & No break & $3(2.9)$ & $9(9.3)$ & $12(6)$ \\
\hline & Every $20 \mathrm{~min}$ & $30(29.1)$ & $14(14.4)$ & $44(22)$ \\
\hline & Every hour & $18(17.5)$ & $8(8.2)$ & $26(13)$ \\
\hline & When tired & $52(50.5)$ & $66(68)$ & $118(59)$ \\
\hline & Total & $103(100)$ & $97(100)$ & $200(100)$ \\
\hline
\end{tabular}

TABLE 2: Age groups and hours spent on computer per day.

\begin{tabular}{lcc}
\hline Age group & $2-5$ hours $(\%)$ & $6-9$ hours $(\%)$ \\
\hline$<25$ & $1(0.5)$ & $4(2.0)$ \\
$25-29$ & $10(5.0)$ & $75(37.5)$ \\
$30-35$ & $47(23.5)$ & $20(10.0)$ \\
$36-40$ & $36(18.0)$ & $7(3.5)$ \\
\hline
\end{tabular}

elsewhere: $67.4 \%$ in Sri Lanka [8], 74.0\% in Nigeria [33], and $80.3 \%$ in Chennai, India [34]. In the Sri Lankan study, Ranasinghe et al. followed 2210 computer users of two telecommunication institutes in nine provinces for a year. The yearlong follow-up with significantly larger sample size and inclusion of older subjects (age range:18-60 years) may explain the higher prevalence of CVS cases in the Sri Lankan study [8] compared to our study. Again, in that study, a higher prevalence of CVS (69.5\%) was reported for females in a male dominated study sample contrasting our finding of higher CVS cases (54.4\%) in males. The higher prevalence of CVS among males in our present work may be a direct influence of the imbalanced gender distribution of study participants.

We also observed that approximately $50 \%$ of the CVS cases were within the age bracket of 25-29 years. This finding is corroborated by the fact that young individuals tend to use computers for long hours and the same reason may hold for the higher prevalence of CVS reported for medical and engineering students in Chennai, India [34]. It is important to mention that in addition to including the vulnerable 
TABLE 3: Severity of CVS symptoms among administrators.

\begin{tabular}{|c|c|c|c|c|}
\hline CVS indicator & Never & Moderate & Severe & Total \\
\hline Burning sensation & $26(25.2)$ & $67(65)$ & $10(9.7)$ & $103(100)$ \\
\hline Itching & $26(25.2)$ & $64(62.1)$ & $13(12.6)$ & $103(100)$ \\
\hline Foreign body sensation & $48(46.6)$ & $53(51.5)$ & $2(1.9)$ & $103(100)$ \\
\hline Tearing & $45(43.7)$ & $49(47.6)$ & $9(8.79)$ & $103(100)$ \\
\hline Excessive blinking & $42(40.8)$ & $52(50.5)$ & $9(8.7)$ & $103(100)$ \\
\hline Eye redness & $52(50.5)$ & $45(43.7)$ & $6(5.8)$ & $103(100)$ \\
\hline Eye pain & $38(36.9)$ & $55(53.4)$ & $10(9.7)$ & $103(100)$ \\
\hline Heavy eyelids & $58(56.3)$ & $33(32)$ & $12(11.7)$ & $103(100)$ \\
\hline Dryness & $67(65)$ & $33(32)$ & $3(2.9)$ & $103(100)$ \\
\hline Blurred vision & $41(39.8)$ & $50(48.5)$ & $12(11.7)$ & $103(100)$ \\
\hline Double vision & $72(69.9)$ & $27(26.2)$ & $4(3.9)$ & $103(100)$ \\
\hline Difficulty focusing for near & $71(68.9)$ & $27(26.2)$ & $5(4.9)$ & $103(100)$ \\
\hline Increased sensitivity to light & $36(35)$ & $43(41.7)$ & $24(23.3)$ & $103(100)$ \\
\hline Circle of light around an object & $80(77.7)$ & $18(17.5)$ & $5(4.9)$ & $103(100)$ \\
\hline Feeling that sight is worsening & $67(65)$ & $35(34)$ & $1(1)$ & $103(100)$ \\
\hline Headache & $27(26.2)$ & $53(51.5)$ & $23(22.3)$ & $103(100)$ \\
\hline
\end{tabular}

TABLE 4: Ergonomic measurements of administrators.

\begin{tabular}{|c|c|c|c|c|c|c|}
\hline Ergonomic parameters & Ergonomic practice & CVS case & Non-CVS case & Total & $X$ & $p$ value \\
\hline \multirow{3}{*}{ Viewing angle from eye to top of computer screen } & Poor & $70(68.0)$ & $51(52.6)$ & $121(60.5)$ & \multirow{3}{*}{4.947} & \multirow{3}{*}{0.026} \\
\hline & Good & $33(32.0)$ & $46(47.4)$ & $79(39.5)$ & & \\
\hline & Total & $103(10)$ & $97(100)$ & $200(100)$ & & \\
\hline \multirow{3}{*}{ Viewing angle from eye to center of computer screen } & Poor & $87(84.5)$ & $60(61.9)$ & $147(73.5)$ & \multirow{3}{*}{13.112} & \multirow{3}{*}{0.001} \\
\hline & Good & $16(15.5)$ & $37(38.1)$ & $53(26.5)$ & & \\
\hline & Total & $103(100)$ & $97(100)$ & $200(100)$ & & \\
\hline \multirow{3}{*}{ Viewing angle from eye to bottom of computer screen } & Poor & $51(49.5)$ & $40(41.2)$ & $91(45.5)$ & \multirow{3}{*}{1.380} & \multirow{3}{*}{0.240} \\
\hline & Good & $52(50.5)$ & $57(58.8)$ & $109(54.5)$ & & \\
\hline & Total & $103(100)$ & $97(100)$ & $200(100)$ & & \\
\hline \multirow{3}{*}{ Distance from horizontal to top of computer screen } & Poor & $103(100$ & $68(70.1)$ & $171(85.5)$ & \multirow{3}{*}{36.016} & \multirow{3}{*}{0.001} \\
\hline & Good & $0(0.0)$ & $29(29.9)$ & $29(14.5)$ & & \\
\hline & Total & $103(100)$ & $97(100)$ & $200(100)$ & & \\
\hline \multirow{3}{*}{ Distance from horizontal to bottom of computer } & Poor & $74(71.8)$ & $56(57.7)$ & $130(65.0)$ & \multirow{3}{*}{4.373} & \multirow{3}{*}{0.037} \\
\hline & Good & $29(28.2)$ & $41(42.3)$ & $70(70.5)$ & & \\
\hline & Total & $103(100)$ & $97(100)$ & $200(100)$ & & \\
\hline \multirow{3}{*}{ Distance from horizontal to center of computer screen } & Poor & $71(68.9)$ & $48(49.5)$ & $119(59.5)$ & \multirow{3}{*}{7.840} & \multirow{3}{*}{0.005} \\
\hline & Good & $32(31.1)$ & $49(50.5)$ & $81(40.5)$ & & \\
\hline & Total & $103(100$ & $97(100)$ & $200(100)$ & & \\
\hline \multirow{3}{*}{ Viewing distance from eye to home row of keyboard } & Poor & $79(76.7)$ & $58(59.8)$ & $137(68.5)$ & \multirow{3}{*}{6.616} & \multirow{3}{*}{0.010} \\
\hline & Good & $24(23.3)$ & $39(40.2)$ & $63(31.5)$ & & \\
\hline & Total & $103(100)$ & $97(100)$ & $200(100)$ & & \\
\hline \multirow{3}{*}{ Height of keyboard from the floor } & Poor & $13(12.6)$ & $18(18.6)$ & $31(15.5)$ & \multirow{3}{*}{1.344} & \multirow{3}{*}{0.246} \\
\hline & Good & $90(87.4)$ & $79(81.4)$ & $169(84.5)$ & & \\
\hline & Total & $103(100)$ & $97(100)$ & $200(200)$ & & \\
\hline \multirow{3}{*}{ Light intensity of room } & Poor & $98(95.1)$ & $74(76.3)$ & $172(86.0)$ & \multirow{3}{*}{14.754} & \multirow{3}{*}{0.001} \\
\hline & Good & $5(4.9)$ & $23(23.7)$ & $28(14.0)$ & & \\
\hline & Total & $103(100)$ & $97(100$ & $200(100)$ & & \\
\hline \multirow{3}{*}{ Light intensity between participant and computer } & Poor & $102(99.0)$ & $73(75.3)$ & $175(87.5)$ & \multirow{3}{*}{25.809} & \multirow{3}{*}{0.001} \\
\hline & Good & $1(1.0)$ & $24(24.7)$ & $25(12.5)$ & & \\
\hline & Total & $103(100)$ & $97(100)$ & $200(100)$ & & \\
\hline
\end{tabular}

contact lens wearers in study sample, the presence of neck and shoulder pains counted towards the prevalence of CVS symptoms in the Chennai study. The presence of presbyopia $[9,10]$, uncorrected ametropia $[10,20]$, and contact lens wear [21] may exacerbate visual symptoms frequently reported by CVS patients. To ensure that the reported symptoms were as a result of computer usage and consistent with Mashige et al. [26], persons with the following 
TABle 5: Comparison between ergonomic practice and CVS.

\begin{tabular}{lcccc}
\hline & Cases & Noncases & Total & $\chi$ \\
\hline Poor practice & $93(90.3)$ & $66(68.0)$ & $159(79.5)$ & 15.175 \\
Good practice & $10(9.7)$ & $31(32.0)$ & $41(20.5)$ & 0.001 \\
Total & $103(100)$ & $97(100)$ & $200(100)$ & \\
\hline
\end{tabular}

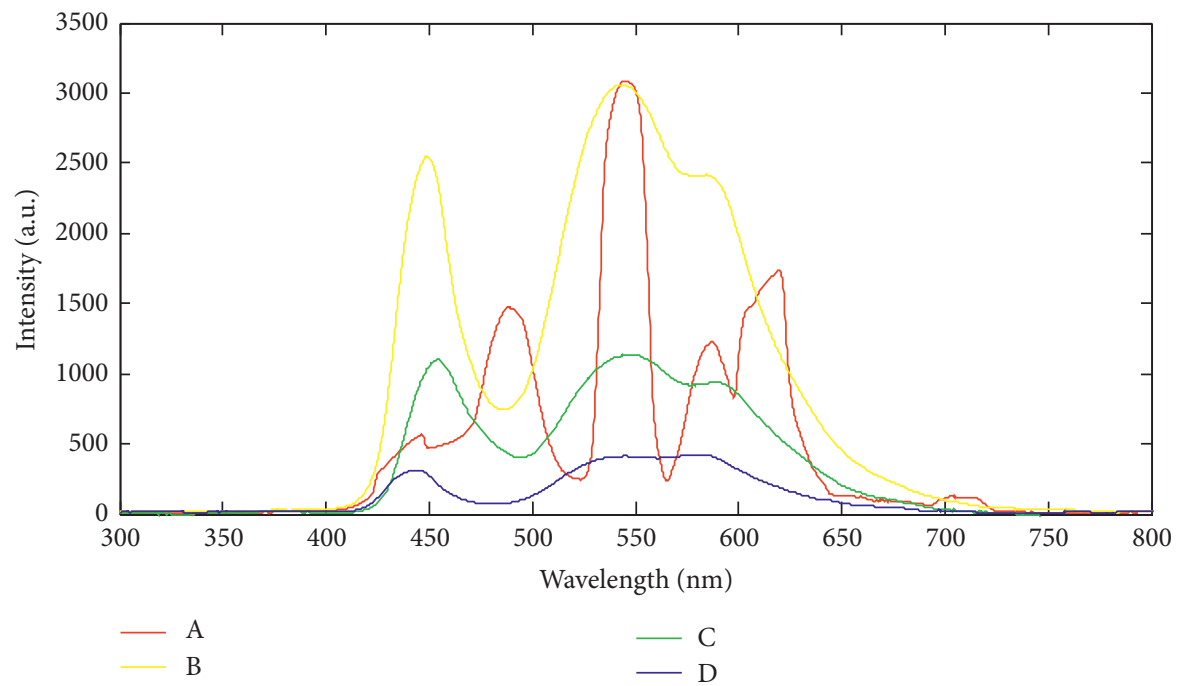

(a)

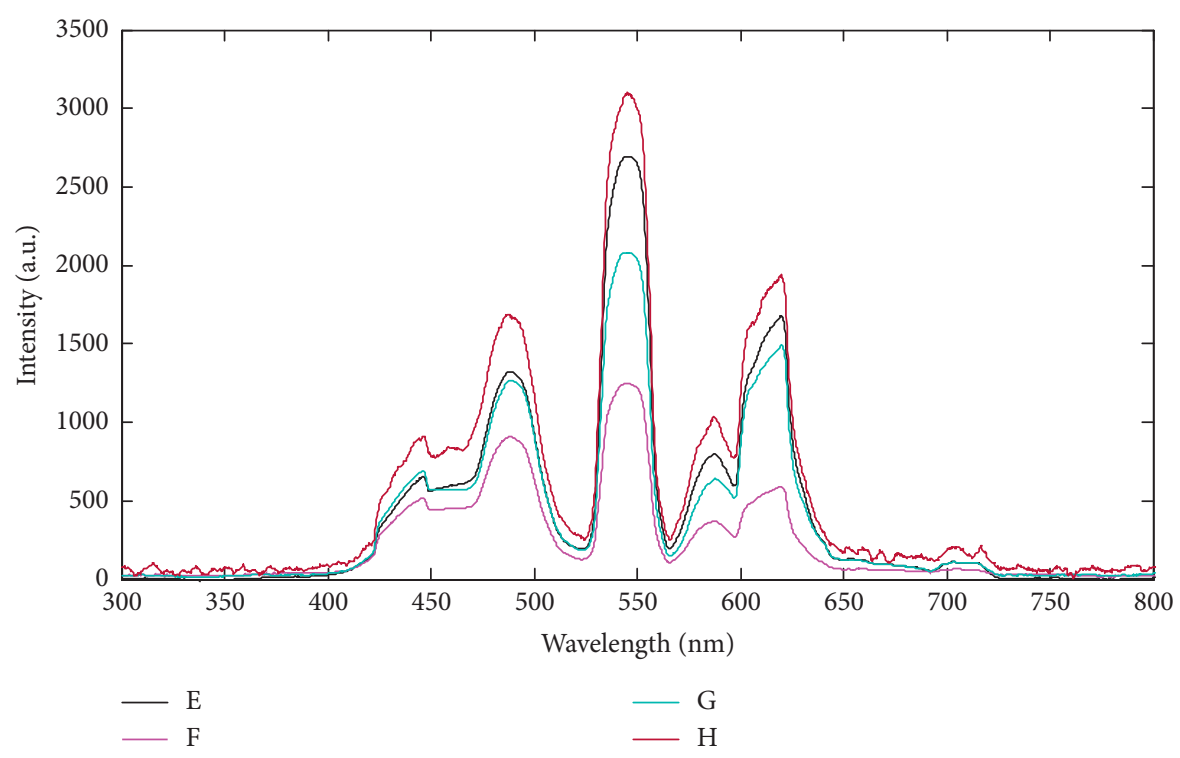

(b)

Figure 2: (a) Spectra of light radiation from different sampled computer screens. (b) Spectra of light radiation from different sampled computer screens.

attributes were excluded from our study sample: early presbyopes, individuals 40 years and above, greater than $\pm 3.75 \mathrm{D}$ refractive error, contact lens wear, systemic and ocular diseases, pregnancy, and use of oral contraceptives.

While headaches and increased sensitivity to light were identified as the most frequent severe CVS symptoms, burning sensation, itching, and eye pain were the most frequent moderate symptoms enumerated by the participants. Rosenfield posits that burning sensation and irritation are due to dryness of the ocular surface caused by infrequent blinking of the eyes during the use of computers [10]. Majority (53.0\%) of the participants reported more than 5 hours of daily screen time without taking regular breaks. Infrequent breaks and prolonged use of computers are 
strongly associated with complaints of dryness of the ocular surface. We also found similar symptoms identified by Sheedy [19] as the five commonest CVS symptoms: eyestrain, headache, blurred vision, dry eyes, and neck/back pain.

Poor workstation or office ergonomic practices account for several visual symptoms and all non-eye-related symptoms associated with the use of computers [22]. Inappropriate positioning of the computer and its accessories and improper viewing angles cause aching of the muscles of the neck, shoulder, and back [4, 22, 23]. Severe musculoskeletal complaints were also reported by 63 out of the 103 participants, classified as having CVS, and 45 out of the 97 respondents without CVS. Furthermore, there was a significant association between the presence of CVS and poor ergonomic practices $(\chi=15.175, p=0.001)$. Assessment of the participants' workstations revealed wrong viewing angle to the center of the screen, improper viewing distance, wrong positioning of keyboard, suboptimal office illumination, and improper computer screen brightness. CVS symptoms such as glare and asthenopia are also associated with improper screen brightness, wrong viewing angle and distance, and poor room illumination $[6,26]$. These improper ergonomic practices were more prevalent among the CVS case group. Ranasinghe and colleagues showed that users at workstations which were noncompliant to standard ergonomic recommendations had higher prevalence of CVS [8]. It is important to note that some of the computer screens sampled emitted blue light which has been documented to be injurious to the unprotected eyes [35-37]. Protection of eyes with antireflective lenses or computer screen shields may be helpful. There is, however, no strong evidence backing advantages of using blue light blocking lenses or computer screen shields [38].

Of note, we did not test the association between participants' awareness and the presence of CVS because we did not obtain participants' knowledge on CVS and office ergonomics. Contrary to other studies [25, 34], we did not categorize musculoskeletal pain as a symptom of CVS. Since we were interested in the association between workstation ergonomics and CVS, we did not assess participants' anthropometry information. Even though there is no gold standard to diagnose CVS, we navigated this shortcoming by adopting previously used definitions and criterion to study CVS. It is anticipated that subsequent follow-up studies would take into considerations these limitations.

\section{Conclusion}

There is a high prevalence of computer vision syndrome among university administrative staff. Younger employees had prolonged daily use of computers, increasing their chances of developing CVS. Incorrect viewing angle and distance as well as poor office lighting are among the many ergonomics factors associated with CVS among computer users. Further studies in larger sample will help to better understand the magnitude of the burden CVS poses to the health system and national economy. As access to computer continues to become universal at many workplaces, increasing public awareness and compliance to recommended office ergonomics are necessary measures to mitigate the rising prevalence in CVS cases.

\section{Data Availability}

All data generated or analyzed during this study are included in this article.

\section{Conflicts of Interest}

The authors declare that they have no conflicts of interest.

\section{Acknowledgments}

We are grateful to the Directorate of Human Resource and Directorate of Finance of the University of Cape Coast for providing the relevant staff data which were needed for the study. We are also grateful to the staff who volunteered to participate in this study in spite of their busy work schedule. Finally, we thank the Coordinator of the Laser and Fibre Optic Centre, Department of Physics of the University of Cape Coast, for providing the needed equipment for aspects of the study.

\section{References}

[1] C. Blehm, S. Vishnu, A. Khattak, S. Mitra, and R. W. Yee, "Computer vision syndrome: a review," Survey of Ophthalmology, vol. 50, no. 3, pp. 253-262, 2005.

[2] J. D. Singh, Computers and Your Health-Protecting Yourself from Computer Related Health Issues, JD Biz Publishing, Mendon, UT, USA, 2015.

[3] N. A. Charpe and V. Kaushik, "Computer vision syndrome (CVS): recognition and control in software professionals," Journal of Human Ecology, vol. 28, no. 1, pp. 67-69, 2009.

[4] A. Klussmann, H. Gebhardt, F. Liebers, and M. A. Rieger, "Musculoskeletal symptoms of the upper extremities and the neck: a cross-sectional study on prevalence and symptompredicting factors at visual display terminal (VDT) workstations," BMC Musculoskeletal Disorders, vol. 9, p. 96, 2008.

[5] J. Torrey, "Understanding computer vision syndrome," Employment Relations Today, vol. 30, no. 1, pp. 45-51, 2003.

[6] J. K. S. Parihar, V. K. Jain, P. Chaturvedi, J. Kaushik, G. Jain, and A. K. S. Parihar, "Computer and visual display terminals (VDT) vision syndrome (CVDTS),” Medical Journal Armed Forces India, vol. 72, no. 3, pp. 270-276, 2016.

[7] A. Toomingas, M. Hagberg, M. Heiden, H. Richter, K. E. Westergren, and E. W. Tornqvist, "Risk factors, incidence and persistence of symptoms from the eyes among professional computer users," Work, vol. 47, no. 3, pp. 291-301, 2014.

[8] P. Ranasinghe, W. S. Wathurapatha, Y. S Perera et al., "Computer vision syndrome among computer office workers in a developing country: an evaluation of prevalence and risk factors," BMC Research Notes, vol. 9, p. 150, 2016.

[9] A. Dessie, F. Adane, A. Nega, S. D. Wami, and D. H. Chercos, "Computer vision syndrome and associated factors among computer users in debre tabor town, northwest Ethiopia," J Environ Public Health, vol. 2018, Article ID 4107590, 8 pages, 2018. 
[10] American Optometric Association, Guide to the Clinical Aspects of Computer Vision Syndrome, American Optometric Association, St. Louis, MO, USA, 1995.

[11] M. Gangamma, M. Poonam, and M. Rajagopala, "A clinical study on "Computer vision syndrome" and its management with Triphala eye drops and saptamrita lauha," AYU (An International Quarterly Journal of Research in Ayurveda), vol. 31, no. 2, p. 236, 2010.

[12] M. Rosenfield, "Computer vision syndrome: a review of ocular causes and potential treatments," Ophthalmic and Physiological Optics, vol. 31, no. 5, pp. 502-515, 2011.

[13] E. Futyma and M. E. Pros, "Evaluation of the visual function in employees working with computers," Klinika Oczna, vol. 104, no. 3, pp. 257-259, 2002.

[14] J. C. Izquierdo, M. Garcia, C. Buxo, and N. J. Izquierdo, "Factors leading to the computer vision syndrome: an issue at the contemporary workplace," Boletín de la Asociación Médica de Puerto Rico, vol. 99, no. 1, pp. 21-28, 2007.

[15] F. Leccese, G. Salvadori, M. Oner, and T. Kazanasmaz, "Exploring the impact of external shading system on cognitive task performance, alertness and visual comfort in a daylit workplace environment," Indoor and Built Environment, pp. 1-14, 2019.

[16] B. R. Blais, "Visual ergonomics of the office workplace," Chemical Health and Safety, vol. 6, no. 4, pp. 31-38, 1999.

[17] K. Kanitkar, A. N. Carlson, and Y. Richard, "Ocular problems associated with computer use: the ever-increasing hours spent in front of video display terminals have led to a corresponding increase in visuals and physical ills," Review of Ophthalmology, vol. 22, no. 12, pp. 3-4, 2005.

[18] Z. Yan, L. Hu, H. Chen, and F. Lu, "Computer vision syndrome: a widely spreading but largely unknown epidemic among computer users," Computers in Human Behavior, vol. 24, no. 5, pp. 2026-2042, 2008.

[19] J. E. Sheedy, "Vision problems at video display terminals: a survey of optometrists," Journal of the American Optometric Association, vol. 63, no. 10, pp. 687-692, 1992.

[20] M. Rosenfield, J. Hue, R. Huang, and Y. Bababekova, "Uncorrected astigmatism and computer vision syndrome," Investigative Ophthalmology \& Visual Science, vol. 52, no. 14, p. $2815,2011$.

[21] N. P. Wiggins, K. M. Daum, and C. A. Snyder, "Effects of residual astigmatism in contact lens wear on visual discomfort in VDT use," Journal of the American Optometric Association, vol. 63, pp. 177-181, 1992.

[22] J. Anshel, Visual Ergonomics Handbook, pp. 45-50, Taylor \& Francis Group, Abingdon, UK, 2005.

[23] D. R. Ankrum, "Visual ergonomics in the office-guidelines," Occupational Health \& Safety, vol. 68, no. 7, pp. 64-74, 1999.

[24] F. Leccese, G. Salvadori, and M. Rocca, "Visual ergonomics of video-display-terminal workstations: field measurements of luminance for various display settings," Displays, vol. 42, pp. 9-18, 2016.

[25] S. C. Reddy, C. Low, Y. Lim, L. Low, F. Mardina, and M. Nursaleha, "Computer vision syndrome: a study of knowledge and practices in university students," Nepalese Journal of Ophthalmology, vol. 5, no. 2, pp. 161-168, 2013.

[26] K. P. Mashige, N. Ramprasad, and O. Oduntan, "A study of ergonomic factors leading to computer vision syndrome among computer users," Ergonomics SA, vol. 25, no. 1, pp. 3-12, 2013.

[27] K. P. Mashige, "Occupational health southern Africa-computer-related symptoms in the workplace: causes and preventive strategies: back to basics," Occupational Health Southern Africa, vol. 20, no. 3, pp. 13-17, 2014.

[28] M. D. M. Seguí, J. Cabrero-García, A. Crespo, J. Verdú, and E. Ronda, "A reliable and valid questionnaire was developed to measure computer vision syndrome at the workplace," Journal of Clinical Epidemiology, vol. 68, no. 6, pp. 662-673, 2015.

[29] Workers' Compensation Board (WCB) of British Columbia, "How to make your computer workstation fit you," 2018, https://www.worksafebc.com/en/resources/health-safety/ books-guides/how-to-make-your-computer-workstationfit-you.

[30] Oregon Occupational Safety and Health Agency, "Evaluating your computer workstation: how to make it work for you," 2018, http://ehs.oregonstate.edu/sites/ehs.oregonstate.edu/files/ pdf/ergo/or-osha_evaluating_your_computer_workstation.pdf.

[31] American National Standards Institute, ANSI/HFES 100-2007, Human Factors engIneering of Computer Workstations, Human Factors and Ergonomics Society, Santa Monica, CA, USA, 2007.

[32] D. B. Kumah, K. O. Akuffo, D. E. Affram, E. Ankamah, and E. A. Osae, "Ergonomic challenges of employees using computers at work in a tertiary institution in Ghana," $O p$ tometry: Open Access, vol. 1, no. 2, p. 107, 2016.

[33] R. Akinbinu and Y. Mashalla, "Knowledge of computer vision syndrome among computer users in the workplace in Abuja, Nigeria," Journal of Physiology and Pathophysiology, vol. 4, no. 4, pp. 58-63, 2013.

[34] M. Logaraj, V. Madhupriya, and S. Hegde, "Computer vision syndrome and associated factors among medical and engineering students in Chennai," Annals of Medical and Health Sciences Research, vol. 4, no. 2, pp. 179-185, 2014.

[35] B. W. Van Der Burght, M. Hansen, J. Olsen et al., "Early changes in gene expression induced by blue light irradiation of A2E-laden retinal pigment epithelial cells," Acta Ophthalmologica, vol. 91, no. 7, pp. e537-e545, 2013.

[36] P. V. Algvere, J. Marshall, and S. Seregard, "Age-related maculopathy and the impact of blue light hazard," Acta Ophthalmologica Scandinavica, vol. 84, no. 1, pp. 4-15, 2006.

[37] G. Tosini, I. Ferguson, and K. Tsubota, "Effects of blue light on the circadian system and eye physiology," Molecular Vision, vol. 22, pp. 61-72, 2016.

[38] J. G. Lawrenson, C. C. Hull, and L. E. Downie, “The effect of blue-light blocking spectacle lenses on visual performance, macular health and the sleep-wake cycle: a systematic review of the literature," Ophthalmic and Physiological Optics, vol. 37, no. 6, pp. 644-654, 2017. 